\title{
MATHEMATICAL MODELING SINGULARLY PERTURBED PROCESSES OF WATER SOFTENING ON SODIUM-CATIONITE FILTERS
}

\author{
Andrii Safonyk ${ }^{1}$, Ihor Prysiazhniuk ${ }^{2}$, Olena Prysiazhniuk ${ }^{1}$, Oleksandr Naumchuk ${ }^{1}$ \\ ${ }^{1}$ National University of Water and Environmental Engineering, Department of Automation, Electrical Engineering and Computer-Integrated Technologies, \\ ${ }^{2}$ Rivne State University of Humanities, Department of Mathematics
}

\begin{abstract}
Mathematical model of the process of water softening using ion exchange pre-treatment of waters to desalination, with a view to removal of scale forming components, such as calcium and magnesium, are formed in the paper. In this process, no additional chemicals, except for brines formed during desalination, are required for regeneration of ion-exchanger in operation cycles. An asymptotic approximation of a solution of a corresponding model problem is constructed. Theoretical description and modelling assumptions included the set of differential equations of mass balance, initial, boundary and operational conditions. The paper deals with the development of a computer model for description and prediction of the performance of ion exchange columns.
\end{abstract}

Keywords: mathematical modelling, ion exchange, adsorption

\section{MODELOWANIE MATEMATYCZNE SYNGULARNEGO ZABURZONEGO PROCESU ZMIĘKCZANIA WODY W FILTRACH SODOWO-KATIONOWYCH}

\begin{abstract}
Streszczenie. W pracy opracowano matematyczny model procesu zmiękczania wody przy użyciu wstępnej obróbki wody poprzez wymianę jonowa do odsalania $w$ celu usunięcia składników tworzacych kamień, takich jak wapń i magnez. W procesie tym dla regeneracji wymiennika jonowego w cyklach roboczych nie trzeba wykorzystywać dodatkowych chemicznych czynników za wyjatkiem solanek, które powstaja podczas odsalania. Opracowano asymptotyczne przybliżenie odpowiedniego rozwiąania z modelem. Opis teoretyczny i założenia modelu obejmuja szereg równań różniczkowych bilansu masy, warunków poczatkowych, granicznych i eksploatacyjnych. Rozpatrzono opracowanie modelu komputerowego dla opisu i prognozowania działania kolumn wymiany jonowej.
\end{abstract}

Slowa kluczowe: modelowanie matematyczne, wymiana jonowa, absorpcja

\section{Introduction}

Hight salinity levels in wastewater usually have negative consequences to equipment that comes in contact with such water, for example boiler room installations. Though many techniques have been developed to solve the problem, high capital costs or energy consumption have hindered their application in wider areas. One economical solution of reusing the wastewater of high salinity is applying natural or synthetic zeolites as ion exchanger and adsorbent.

The principle of work of softeners is based on the process of replacing calcium, magnesium and other metals with cations of sodium (or hydrogen). The process of softening the water is carried out by filtration from the top down through the cationite layer of insoluble nanoporous granules about $1 \mathrm{~mm}$ in diameter. After exhausting the cation exchanger, the quality of softening is significantly worse. To restore the ion-exchange resin's properties, an automatic transition to the regeneration mode occurs by passing through a layer of salt solution.

The mechanisms governing the salt removal process by zeolites are mainly ion exchange, adsorption, and salt storage. Factors such as zeolite's geochemical properties, $\mathrm{pH}$, co-existing anions, concentration, valency, surface charge, and experimental conditions all influence the ion exchange process [6]. The adsorption kinetics of $\mathrm{Ca}$ on zeolites is mostly a pseudosecond-order type with an exothermic nature. Calcium removal by zeolites appears to be an effective water treatment technology for maximizing the beneficial use of poor-quality wastewater. However, challenges still remain and further work is required in areas of lowering operational cost and improving zeolite's regenerability. To overcome these challenges, researchers could make more efforts in technical improvements, including alterable surface properties and the incorporation of other approaches to achieve better salt removal outcome.

\section{Literature review}

The reaction of ion exchange, which is the basis of the cation exchange method of water softening, is a complex multi-stage process. On the basis of the known laws of sorption dynamics in [4] a one-dimensional mathematical model of the cation exchange filter operation under the conditions of the nonequilibrium dynamics of the mixed diffusion kinetics of exchange of $\mathrm{Na}^{+}$cations on $\mathrm{Ca}^{2+}$ cations was proposed. In this model, the mutual influence of diffusion of some cations on the diffusion of others was not taken into account. In addition, since different stages of the described process proceed at different speeds, for some members of the mathematical model equations, small parameters appear, that is, the model is perturbed, and the solution of the corresponding model problem permits the asymptotic development of a small parameter [5].

In this paper, the asymptotic approximation of the solution of a singularly perturbed problem of convection diffusionadsorption transfer of a solution of calcium salts through a cationite layer is explained.

\section{Formulation of the problem}

On the basis of existing ideas $[1,6]$, when softening water in cationite, in the theory of ion exchange, it is customary to consider three stages of cation exchange: a) delivery of the cation from the cation-exchange filter solution to the surface of the cationite grain; b) the penetration of this cation into the inside of the cationite grain; c) chemical interaction of the cation with the functional group of the cation exchanger. All the listed stages usually proceed simultaneously, but their flow rates are different. In this regard, the equations describing the course of the most slowly proceeding ion exchange stage in the case under consideration will be described by equations of external diffusion transfer (kinetics) in the first stage and inside diffusion transfer (kinetics) in the second stage.

Thus, based on the foregoing, and taking into account the existing ideas, the process of water softening in the ionexchange filter consists of the following steps:

- convection-diffusion-adsorption transfer of cations $\mathrm{Ca}^{2+}$ and $\mathrm{Na}^{+}$in a filtration solution

$$
D_{j} \frac{\partial^{2} c_{j}}{\partial x^{2}}-v(x) \frac{\partial c_{j}}{\partial x}-\frac{\partial u_{j}}{\partial t}=\sigma \frac{\partial c_{j}}{\partial t},
$$

- diffusion transfer inside the grain of cation

$$
\bar{D}_{j}\left(\frac{\partial^{2} q_{j}}{\partial r^{2}}+\frac{2}{r} \frac{\partial q_{j}}{\partial r}\right)=\frac{\partial q_{j}}{\partial t},
$$


- transfer of cations from the solution to the cation exchange granule

$$
\frac{\partial u_{i}}{\partial t}=\left.w \bar{D}_{i} \frac{\partial q_{i}}{\partial r}\right|_{r=R},
$$

where $c_{j}(x, t)$ - concentration of sodium $(j=1)$ and calcium $(j=2)$ cations in the water, $u_{j}(x, t)$ - concentration of cations on the surface of cationite grains, $q_{j}(x, r, t)$ - concentration of cations in the grains, $v(x)$ - filtration rate, $D_{j}=\varepsilon d d_{j}$ and $\bar{D}_{j}=\varepsilon \bar{d}_{j}-$ coefficients of diffusion of a $j$ component in a filter and in cationite grains, $\varepsilon>0-$ a small parameter characterizing the predominance of the convective and adsorption component of the process over the diffusion, $w$ - specific surface area of grain of cationite.

The system (1) - (3) is supplemented by the initial and boundary conditions:

$$
\begin{gathered}
c_{j}(x, 0)=c_{j}^{0}(x), u_{j}(x, 0)=u_{j}^{0}(x), q_{j}(x, r, 0)=0, \\
c_{j}(0, t)=c_{j}^{*}(t),\left.\frac{\partial q_{j}(x, r, t)}{\partial r}\right|_{r=0}=0 .
\end{gathered}
$$

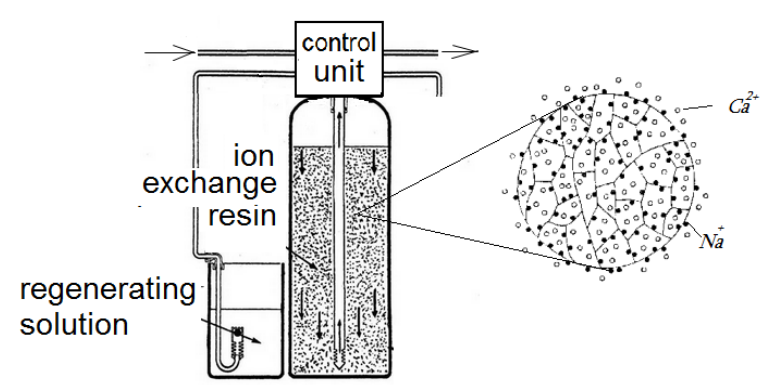

Fig. 1. Ion exchange column

The ion-exchange isotherm equation (assuming that the coefficients of activity of $\mathrm{Ca}^{2+}$ and $\mathrm{Na}^{+}$cation equal to 1 [6]) have the form:

$$
\frac{u_{1}}{\sqrt{u_{2}}}=k_{1,2} \frac{\tilde{c}_{1}}{\sqrt{\tilde{c}_{2}}} .
$$

where $\tilde{c}_{1}, \tilde{c}_{2}-$ equilibrium concentration of cation in solution at the boundary with the surface of cationite grains, $k_{1,2}$ - constant of ion exchange equilibrium. Conditions for the preservation of electroneutrality and constant absorption capacity is $\tilde{c}_{1}+\tilde{c}_{2}=c_{a}$ and $u_{1}+u_{2}=u_{a}$.

The following assumptions are taken when compiling the model: the interaction of cations in the liquid and solid phases is absent, in particular, this substance is present in the liquid and solid phases mainly in the same form; the exchange of cations of sodium and calcium is independent of the presence of other cations; at each time, the cationic pairs that are in solution and adsorbed by the cationite grains are in equilibrium, which makes it possible to set $c_{j}=\tilde{c}_{j}$ when deriving equation (6), introducing the appropriate correction to the constant $k_{1,2}$; a layer of a cation exchanger consists of grains (granules) of spherical shape with conditional radius $R$, to which, according to well-known recommendations, grains (particles) of any shape can be given. Note that the latter have a microporous structure, which ensures the outflow of cations into their pore space.

\section{Materials and methods}

We introduce dimensionless quantities as follows $\tilde{x}=x / l$, $\tilde{r}=r / R, \tilde{t}=t \cdot v / l \cdot \sigma$ :

$$
\begin{gathered}
\frac{\partial c_{j}}{\partial \tilde{t}}=\frac{D_{j}}{v \cdot l} \frac{\partial^{2} c_{j}}{\partial \tilde{x}^{2}}-\frac{v(\tilde{x})}{v} \frac{\partial c_{j}}{\partial \tilde{x}}-\left.\frac{w \cdot \bar{D}_{j} \cdot l}{v \cdot R}\left(\frac{\partial q_{j}}{\partial \tilde{r}}\right)\right|_{\tilde{r}=1}, \\
\frac{\partial q_{j}}{\partial \tilde{t}}=\frac{l \cdot \bar{D}_{j}}{v \cdot R^{2}}\left(\frac{\partial^{2} q_{j}}{\partial \tilde{r}^{2}}+\frac{2}{\tilde{r}} \frac{\partial q_{j}}{\partial \tilde{r}}\right) .
\end{gathered}
$$

The case of the predominance of the convective component of the mass transfer on diffusion and mass transfer is considerer, that is when $\varepsilon=\frac{D_{j}}{v \cdot l}=\frac{1}{P e}$ is a small parameter ( $P e$ is the Peclet number) $\left(v \geq v(x)>v_{*}>>\varepsilon>0\right)$. Two other options $\frac{w \cdot \bar{D}_{j} \cdot l}{v \cdot R}$ and $\frac{l \cdot \bar{D}_{j}}{v \cdot R^{2}}$ can be an arbitrary. Since $w=\frac{3(1-\sigma)}{R}$ [4], after marking the variable $\mu=\frac{l \cdot \bar{D}_{j}}{v \cdot R^{2}}$, we get $\frac{w \cdot \bar{D}_{j} \cdot l}{v \cdot R}=3(1-\sigma) \mu$. Thus, in the case when $l \cdot \bar{D}_{j}<<v \cdot R^{2}$, get a system with two small parameters $\varepsilon$ and $\mu$. Next we evaluate the ratio of parameters $\varepsilon$ and $\mu$. Generally speaking, different cases of correlation of these parameters are possible: $\mu=\beta \cdot \varepsilon^{\alpha}$, where $\alpha$ is arbitrary real number, $\beta$ is positive finite (not commensurate with the given parameters) number. In particular, we considered the case of the values of diffusion coefficients $D_{j}$ and $\bar{D}_{j}$ are values of order $10^{-5}$ and $10^{-15} \mathrm{~m}^{2} / \mathrm{s}$ respectively. In this case, the parameters $\varepsilon$ and $\mu$ are values of one order.

Asymptotic approximation of the solution of the problem (7) (8) are looking for in the form of asymptotic series [3,5] (back to the notation of variables $x, r, t$, meaning that it is dimensional variables):

$$
\begin{gathered}
c_{j}(x, t)=c_{j 0}(x, t)+\varepsilon c_{j 1}(x, t)+\ldots \varepsilon^{n} c_{j n}(x, t)+\Pi_{j 0}(\xi, t)+ \\
+\varepsilon \Pi_{j 1}(\xi, t)+\ldots+\varepsilon^{n+1} \Pi_{j n+1}(\xi, t)+R_{j n}^{1}(x, t, \varepsilon), \\
q_{j}(x, r, t)=q_{j 0}(x, r, t)+\ldots+\varepsilon^{n} q_{j n}(x, r, t)+F_{j 0}(x, \rho, t)+\varepsilon^{1 / 2} F_{j 1 / 2}(x, \rho, t)+ \\
+\ldots+\varepsilon^{i / 2} F_{j i / 2}(x, \rho, t)+\ldots+\varepsilon^{n+1} F_{j n+1}(x, \rho, t)+R_{j n}^{2}(x, r, t, \varepsilon),
\end{gathered}
$$

where $c_{j i}(x, t), \quad q_{j i}(x, r, t) \quad(i=\overline{0, n})$ is the members of the corresponding regular parts of the asymptotic series, $\Pi_{j i}(\xi, t) \quad(i=\overline{0, n+1}), \quad F_{j i / 2}(x, \rho, t) \quad(i=\overline{0,2 n+1})$ is functions of the type of adjoining layer in the vicinity $x=1$ and $\quad r=1, \quad \xi=(l-x) \cdot \varepsilon^{-1} \quad$ and $\quad \rho=(1-r) \cdot \varepsilon^{-1 / 2}$ is the corresponding regularizing transformations, $R_{n}^{1}, R_{n}^{2}$ is the residual members.

Substituting (9), (10) into (7) - (8) and equating the coefficients in the same degrees of $\varepsilon$ we obtain for each $i=\overline{0, n}$ the tasks, analogously to [3]:

$$
\left\{\begin{array}{l}
\frac{\partial q_{j i}(x, \rho, t)}{\partial t}=g_{i}(x, \rho, t), \\
q_{j i}(x, \rho, 0)=h_{i}(x, \rho),
\end{array}\right.
$$




$$
\left\{\begin{array}{l}
v(x) \frac{\partial}{\partial x} c_{j i}(x, t)+\sigma_{1} \frac{\partial}{\partial t} c_{j i}(x, t)=\phi_{i}(x, t), \\
c_{j i}(x, 0)=\varphi_{j i}^{1}(x), \quad c_{j i}(0, t)=\varphi_{j i}^{2}(t),
\end{array}\right.
$$

where $g_{j 0}(x, \rho, t)=0, h_{j 0}(x, \rho)=0$,

$$
\begin{gathered}
g_{j i}(x, \rho, t)=\bar{d}_{j}\left(\frac{\partial^{2}}{\partial r^{2}} q_{j i-1}(x, \rho, t)-(2 / r) \frac{\partial}{\partial r} q_{j i-1}(x, \rho, t)\right), \\
h_{j i}(x, \rho)=0(i=\overline{1, n}), \phi_{j 0}(x, t)=0, \varphi_{j i}^{1}(x)=0, \varphi_{j i}^{2}(t)=0, \\
\varphi_{j 0}^{1}(x)=c_{j}^{0}(x), w_{j 0}^{2}(t)=c_{j}^{*}(t), \phi_{j i}(x, t)=d_{j} \frac{\partial^{2}}{\partial x^{2}} c_{j i-1}(x, t)- \\
-w \bar{d}_{j}\left(\frac{\partial}{\partial r} q_{j i-1}(x, 1, t)+\frac{\partial}{\partial r} F_{j i-1}(x, 1, t)+\varepsilon^{\frac{1}{2}} \frac{\partial}{\partial r} F_{j i-\frac{1}{2}}(x, 1, t)\right) .
\end{gathered}
$$

Functions $\Pi=\sum_{i=0}^{i+1} \varepsilon^{i} \Pi_{i}(\xi, t)$ and $F=\sum_{i=0}^{2 n+2} \varepsilon^{\frac{i}{2}} F_{\frac{i}{2}}(x, \rho, t)$ are constructed for the purpose of fulfilling the second one of the boundary conditions (5) and conditions (6) respectively. Taking into account the ratio $\frac{\partial}{\partial x}=\frac{\partial}{\partial \xi}\left(-\frac{1}{\varepsilon}\right), \frac{\partial^{2}}{\partial x^{2}}=\frac{1}{\varepsilon^{2}} \frac{\partial^{2}}{\partial \xi^{2}}$, $\frac{\partial}{\partial r}=\frac{\partial}{\partial \rho}\left(-\frac{1}{\sqrt{\varepsilon}}\right), \frac{\partial^{2}}{\partial r^{2}}=\frac{1}{\varepsilon} \frac{\partial^{2}}{\partial \rho^{2}}$, and Taylor series expansions of functions $v(1-\varepsilon \xi)$ and $\frac{2}{1-\sqrt{\varepsilon} \rho}$ in the vicinity $x=1$ and $r=1$, we get a task to find the boundary functions [2]:

$$
\begin{gathered}
\left\{\begin{array}{l}
d_{j} \frac{\partial^{2}}{\partial \xi^{2}} \Pi_{j i}(\xi, t)+v(1) \frac{\partial}{\partial \xi} \Pi_{j i}(\xi, t)=\mu_{j i}(\xi, t), \\
\Pi_{j i}(0, t)=v_{j i}(t),\left.\Pi_{j i}(\xi, t)\right|_{\xi \rightarrow \infty} \rightarrow 0,
\end{array}\right. \\
\mu_{j 0}(\xi, t)=0, \mu_{j i}(t, \xi)=\sigma \frac{\partial}{\partial t} \Pi_{j i-1}(\xi, t)+ \\
+v^{\prime}(1) \xi \frac{\partial}{\partial \xi} \Pi_{j i-1}(\xi, t)-\frac{1}{2} v^{\prime \prime}(1) \xi^{2} \frac{\partial}{\partial \xi} \Pi_{j i-2}(\xi, t)+ \\
+\ldots+(-1)^{i} v^{(i)}(1) \xi \frac{\partial}{\partial \xi} \Pi_{j 0}(\xi, t)(i=\overline{1, n+1}, \\
v_{j i}(t)=-c_{j i}(1, t)(i=\overline{0, n}), v_{j n+1}(t)=0 ; \\
\frac{\partial}{\partial t} F_{j i}(x, \rho, t)=\bar{d}_{j} \frac{\partial^{2}}{\partial \rho^{2}} F_{j i}(x, \rho, t)+\gamma_{j i}(x, \rho, t), \\
F_{j i}(x, \rho, 0)=0, F_{j i}(x, 0, t)=\lambda_{j i}(x, t),\left.\frac{\partial}{\partial \rho} F_{j}(x, \rho, t)\right|_{\rho \rightarrow \infty}=0, \\
\gamma_{j 0}(x, \rho, t)=0, \gamma_{j i}(x, \rho, t)=-\bar{d}_{j} \sum_{m=1}^{2 i} 2 \rho^{m-1} \frac{\partial}{\partial \rho} F_{j i-\frac{m}{2}}(x, \rho, t) \\
(i=\overline{1, n+1}), \lambda_{j i}(x, t)=k_{j}\left(c_{j i}(x, t)+\Pi_{j i}(x, t)\right)(i=\overline{0, n}), \\
\lambda_{j n+1}(x, t)=k_{j}\left(\Pi_{j n+1}(x, t)\right) .
\end{gathered}
$$

Solutions of which obtained with accurately $O\left(\varepsilon^{2}\right)$, for example, in the form:

$$
\begin{gathered}
q_{j 0}(x, r, t)=0, \\
c_{j 0}(x, t)=\left[\begin{array}{l}
c_{j}^{*}(\sigma(t / \sigma-f(x)), t \geq \sigma f(x), \\
c_{j}^{0}\left(f^{-1}(f(x)-t / \sigma)\right), t<\sigma f(x),
\end{array}\right.
\end{gathered}
$$

$$
\begin{aligned}
& c_{j 1}(x, t)=\left[\begin{array}{l}
\int_{0}^{z} \frac{g_{j 1}(\sigma(t / \sigma-f(x)+f(\tilde{x})), \tilde{x})}{v(\tilde{x})} d \tilde{x}, t \geq \sigma f(x), \\
\frac{1}{\sigma} \int_{0}^{t} g_{j 1}\left(\tilde{t}, f^{-1}(\tilde{t} / \sigma-t / \sigma+f(x))\right) d \tilde{t}, t<\sigma f(x) ;
\end{array}\right. \\
& f(x)=\int_{0}^{x} \frac{d \tilde{x}}{v(\tilde{x})}, g_{j i}(x, t)=d_{j} \frac{\partial^{2}}{\partial x^{2}} c_{j i-1}(x, t)- \\
& -w \bar{d}_{j}\left(\frac{\partial}{\partial r} q_{j i-1}(x, 1, t)+\frac{\partial}{\partial r} F_{j i-1}(x, 1, t)+\varepsilon^{\frac{1}{2}} \frac{\partial}{\partial r} F_{j i-\frac{1}{2}}(x, 1, t)\right), \\
& \Pi_{j 0}(\xi, t)=D_{j} \frac{\partial}{\partial \xi} C_{j 0}(1, t) v^{-1}(1) e^{-\frac{v(1)}{D_{j}} \xi} .
\end{aligned}
$$

To assess the remaining members we have:

$$
\left\{\begin{array}{l}
\frac{\partial}{\partial t} R_{j n}^{1}(x, t, \varepsilon)=\varepsilon d_{j} \frac{\partial^{2}}{\partial x^{2}} R_{j n}^{1}(x, t, \varepsilon)-v(x) \frac{\partial}{\partial x} R_{j n}^{1}(x, t, \varepsilon)+\varepsilon^{n+1} b_{j 1}(x, t, \varepsilon), \\
\frac{\partial}{\partial t} R_{j n}^{2}(x, r, t, \varepsilon)=\varepsilon \bar{d}_{j}\left(\frac{\partial^{2}}{\partial r^{2}} R_{j n}^{2}(x, r, t, \varepsilon)+\frac{2}{r} \frac{\partial^{2}}{\partial r} R_{j n}^{2}(x, r, t, \varepsilon)\right)+\varepsilon^{n+1} b_{j 2}(x, r, t, \varepsilon), \\
R_{j n}^{1}(x, 0, \varepsilon)=0, R_{j n}^{1}(0, t, \varepsilon)=0,\left.\frac{\partial R_{j n}^{1}}{\partial x}\right|_{x=1}=0, \\
\left.\frac{\partial R_{j n}^{2}}{\partial r}\right|_{r=0}=0, R_{j n}^{2}(x, 1, t, \varepsilon)=k_{j} R_{j n}^{1}(x, t, \varepsilon), R_{j n}^{2}(x, r, 0, \varepsilon)=0,
\end{array}\right.
$$

where $b_{j 1}(x, t, \varepsilon)$ and $b_{j 2}(x, r, t, \varepsilon)$ is known functions that are the sum of the products of already known members of the series (9), (10), as well as the coefficients for $\varepsilon$ in the Taylor series of function $v(1-\varepsilon \xi)$ in the in the vicinity $x=1$. By requiring a sufficient degree of smoothness and consistency of the initial and boundary conditions, we arrive at the validity of such assertion on the basis of the principle of the maximum type for partial differential equations:

$$
R_{j n}^{1}(x, t, \varepsilon)=O\left(\varepsilon^{n+1}\right), R_{j n}^{2}(x, r, t, \varepsilon)=O\left(\varepsilon^{n+1}\right) .
$$

As a technical object for computer simulation of the process, the filter with the length $l=1 \mathrm{~m}$ was selected, with the filling of particles of a microporous structure with size $R=10^{-5} \mathrm{~m}$.

Computer simulation was carried out with the following parameters:

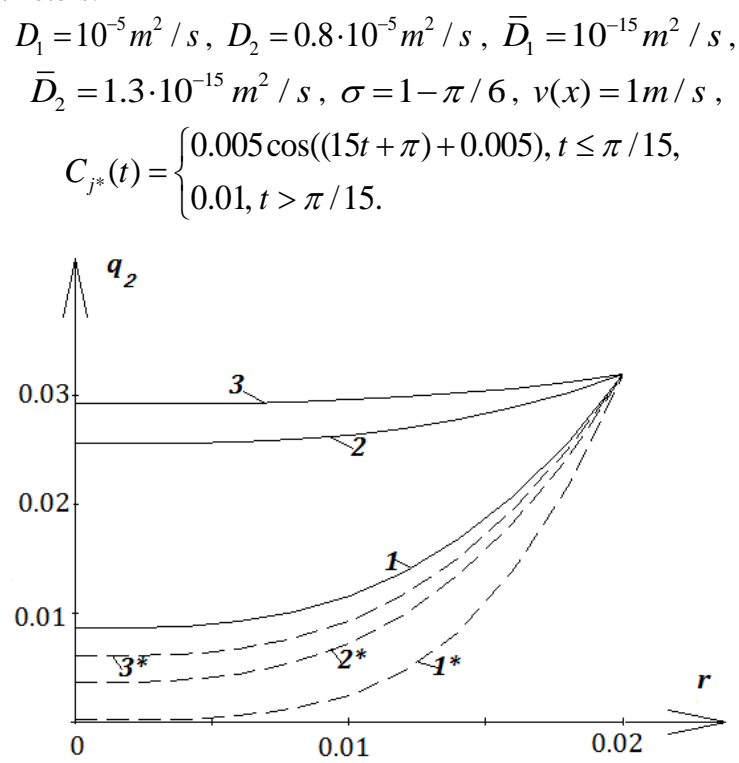

Fig. 2. Distribution of ion concentration in microparticles 
Distribution of the concentration of ion in the interparticle space is shown in Fig. 2. Thus, curve 1-3 corresponds to the solution and $q_{2}(x, t)$ at the time $t=1 h, t=3 h, t=5 h$ when $\bar{d}_{1}=\bar{d}_{2}^{*}=10^{-4} \mathrm{~m}^{2} / \mathrm{h}$ and $\bar{d}_{1}=\bar{d}_{2}^{*}=10^{-4} \mathrm{~m}^{2} / \mathrm{h}\left(1^{*}-3^{*}\right)$.

As the experiment showed, the purification takes place at a certain point in time (contamination of microporous particles). Under given conditions it is $t=5 h$, after which the intensity of cleaning begins to decrease, although the timepieces are not yet completely polluted. The maximum deviation of the calculated concentration value at the filter outlet under given conditions, taking into account adsorption, is $14 \%$.

In Fig. 3, and depicts the distribution of the concentration of pollutant in a microporous particle at moments of time $t=0.5 h, t=0.6 h, t=0.8 h, t=1 h, t=1.8 h$ (curves 1-5) with a center at the point $x=0.2$.

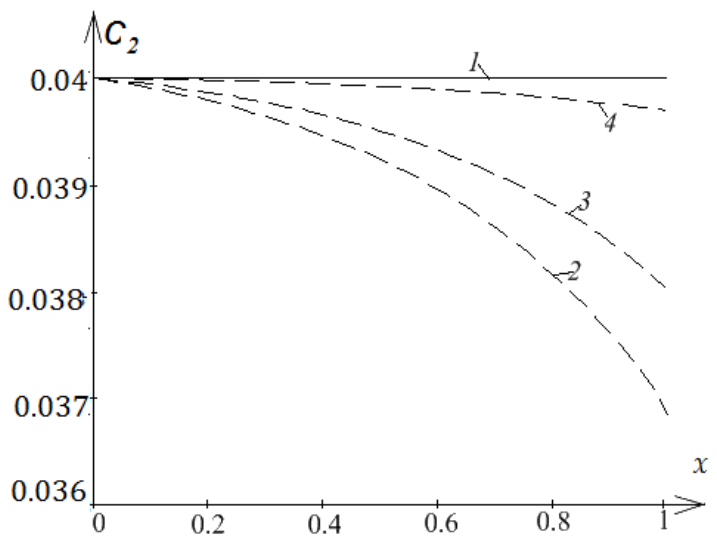

Fig. 3. Distribution of the concentration of pollutant in the interparticle space

\section{D.Sc. Andrii Safonyk}

e-mail: safonik@ukr.net

Professor of the Department of automation, electrical engineering and computer integrated technologies of the Institute of Automation, Cybernetics and Computer Engineering, National University of Water and Environmental Engineering, Rivne, Ukraine.

Engaged in scientific mathematical modeling of natural and technological processes, computer techniques and computer technologies, programming.

ORCID ID: 0000-0002-5020-9051

\section{Ph.D. Ihor Prysiazhniuk}

e-mail: igorpri79@gmail.com

Associate professor of the Department of Mathematics of Rivne State University of Humanities, Rivne, Ukraine.

Engaged in applied and computational mathematics, mathematical modeling of technological processes, numerical modeling and analysis, differential equations in applied mathematics, physics and engineering, computer simulation.

ORCID ID: 0000-0003-4531-1788
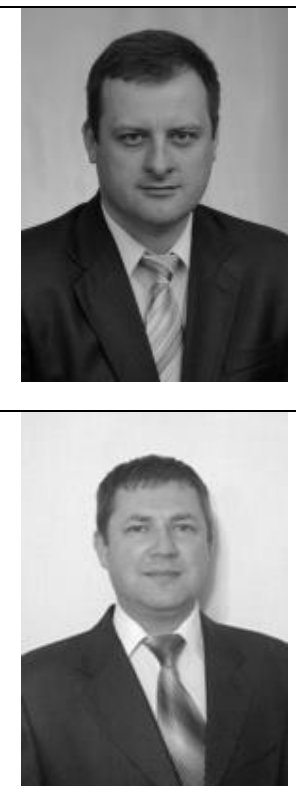

\section{Conclusions}

A mathematical model of a singularly perturbed process of convection diffusion and adsorption mass transfer of ions is formed $\mathrm{Ca}^{2+}$ and $\mathrm{Na}^{+}$in a homogeneous environment particles of microporous structure, which unlike the existing, takes into account the mechanism of convective transfer, as well as specifies the calculation of the distribution of concentration in a microporous medium (filter). The asymptotic approximation of solutions of the corresponding boundary value problem is constructed. $\mathrm{t}$ is confirmed that despite the small velocity of the diffusion mass transfer phenomena in particle pores, over time this significantly affects the distribution of concentration in the part itself and throughout the filter.

\section{References}

[1] Apell J.N., Boyer T.H.: Combined ion exchange treatment for removal of dissolved organic matter and hardness. Water Res. 44, 2010, 2419-2430.

[2] Bomba A. Ya.: Mathematical simulation of the process of aerobic treatment of wastewater under conditions of diffusion and mass transfer perturbations. Journal of Engineering Physics and Thermophysics 2(91)/2018, 318-323.

[3] Bomba A., Klymiuk Yu., Prysiazhniuk I., Prysiazhniuk O., Safonyk A. Mathematical modeling of wastewater treatment from multicomponent pollution by using microporous particles. AIP Conference Proceedings 1773/2016, 1-11.

[4] Obertas I.A.: Modeling of water softening processes on cation exchangers. Reports of the National Academy of Sciences of Ukraine 10/2007, 134-138.

[5] Safonyk A.: Mathematical modelling of regeneration the filtering media bed of granular filters. Advances in Modelling and Analysis C 2(73), 2018, 72-78, [DOI: 10.18280/ama_c.730206].

[6] Tokmacheva M.G., Tikhonova N.A., Khamizovb R.Kh.: Investigation of cyclic self-sustaining ion exchange process for softening water solutions on the basis of mathematical modeling. Reactive and Functional Polymers 8(68), 2008, 1245-1252 [DOI: 10.1016/j.reactfunctpolym.2008.05.004].

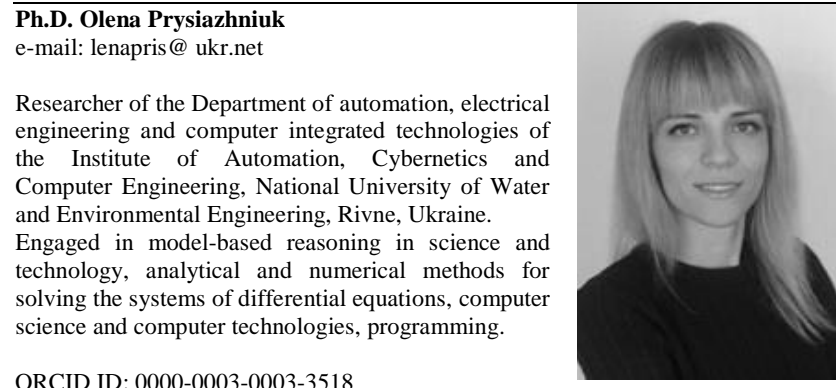

ORCID ID: 0000-0003-0003-3518

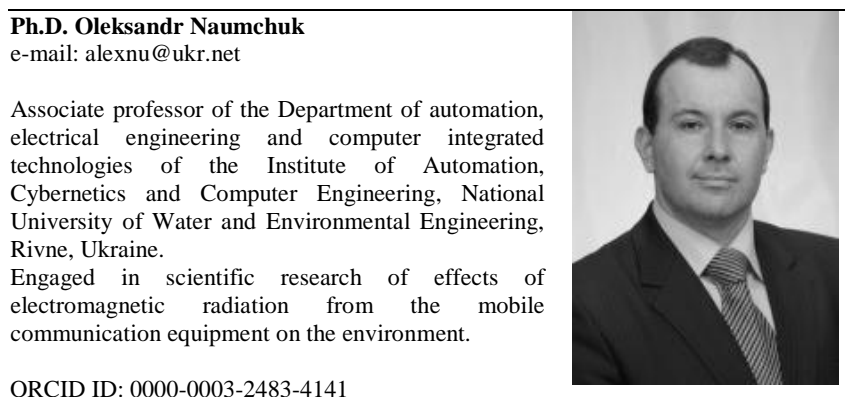

ORCID ID: 0000-0003-2483-414

przyjęto do druku/accepted: 11.03 .2019 